\title{
Gênese Instrumental a partir das metodologias rotação por estações e instrução por pares: um relato de experiência no programa PARFOR
}

\author{
Instrumental Genesis from the methodologies rotation by stations and peer instruction: an
} experience report in the PARFOR program

Génesis instrumental a partir de la rotación de metodologías por estaciones e instrucción entre pares: informe de una experiencia en el programa PARFOR

\begin{abstract}
Resumo
O objetivo deste trabalho é relatar uma experiência didática com metodologias ativas em um curso de formação de professores de matemática no Plano Nacional de Formação de Professores da Educação Básica (PARFOR). O trabalho foi desenvolvido em dois encontros com 20 professores em formação no município de Itacoatiara, interior do Amazonas. As metodologias ativas abordadas foram o modelo de ensino híbrido rotação por estações e a instrução por pares. O referencial teórico subjacente é a Abordagem Instrumental de Pierre Rabardel, com foco na Gênese Instrumental, que estuda a transformação de um artefato em instrumento. Para o percurso metodológico, apoiamo-nos na construção de uma sequência didática inspirada nos princípios das próprias metodologias. A investigação, de cunho qualitativo e delineamento de uma pesquisa ação, teve como instrumentos a observação direta, aplicação de questionários com perguntas abertas e fechadas e com registros fotográficos de cada etapa da atividade. Os resultados alcançados nos permitiram concluir que, apesar de algumas dificuldades com conceitos matemáticos abordados, os professores participaram ativamente das atividades promovendo amplos debates com seus pares e mostraram-se bastante empenhados no aprendizado do conteúdo e dispostos a integrar tais metodologias na sua prática docente. Verificou-se ainda que a maioria dos professores conseguiu alcançar o processo de instrumentalização e que o ambiente dinâmico propiciado pelas metodologias ativas colaborou para a instrumentação.
\end{abstract}

Palavras-chave: Gênese instrumental; Educação matemática; PARFOR.

\begin{abstract}
The objective of this paper is to report a didactic experience with active methodologies in a training course for mathematics teachers in the National Training Plan for Basic Education Teachers (PARFOR). The work was developed in two meetings with 20 teachers in training in the city of Itacoatiara, in the state of Amazonas. The active methodologies approached were the hybrid teaching model rotation by stations and peer instruction. The underlying theoretical framework is Pierre Rabardel's Instrumental Approach, with a focus on Instrumental Genesis, which studies the transformation of an artifact into an instrument. For the methodological path, we rely on the construction of a didactic sequence inspired by the principles of the methodologies themselves. The investigation, qualitative in nature and outlined as an action research, had as instruments direct observation, application of questionnaires with open and closed questions and photographic records of each step of the activity. The results achieved allowed us to conclude that, despite some difficulties with the mathematical concepts addressed, the teachers actively participated in the activities, promoting extensive discussions with their peers and showed great commitment to learning the content and willingness to integrate such methodologies in their teaching practice. It was also found that most teachers were able to achieve the process of instrumentalization and that the dynamic environment provided by the active methodologies contributed to the instrumentation.
\end{abstract}

Keywords: Instrumental genesis; Mathematics education; PARFOR.

\section{Resumen}

El objetivo de este trabajo es reportar una experiencia de enseñanza con metodologías activas en un curso de formación de profesores de matemáticas del Plan Nacional de Formación de Profesores de Educación Básica (PARFOR). El trabajo se desarrolló en dos reuniones con 20 profesores en formación en Itacoatiara, Amazonas. Las metodologías activas abordadas fueron la rotación del modelo de enseñanza híbrido por estaciones y la instrucción entre pares. El marco teórico subyacente es el Enfoque Instrumental de Pierre Rabardel, centrado en la Génesis 
Instrumental, que estudia la transformación de un artefacto en un instrumento. Para el recorrido metodológico, nos basamos en la construcción de una secuencia didáctica inspirada en los principios de las propias metodologías. La investigación, de carácter cualitativo y perfilada como investigación-acción, tuvo como instrumentos la observación directa, la aplicación de cuestionarios con preguntas abiertas y cerradas y el registro fotográfico de cada paso de la actividad. Los resultados obtenidos permitieron concluir que, a pesar de algunas dificultades con los conceptos matemáticos abordados, los profesores participaron activamente en las actividades promoviendo amplias discusiones con sus compañeros y se mostraron muy comprometidos con el aprendizaje de los contenidos y dispuestos a integrar dichas metodologías en su práctica docente. También se comprobó que la mayoría de los profesores lograron el proceso de instrumentalización y que el entorno dinámico proporcionado por las metodologías activas contribuyó a la instrumentación.

Palabras clave: Génesis instrumental; Educación matemática; PARFOR.

\section{Introdução}

Segundo a Base Nacional Curricular Comum (BNCC), considerando os pressupostos da área de Matemática e em articulação com as competências gerais da própria BNCC, o componente curricular de Matemática para o ensino fundamental deve garantir aos alunos o desenvolvimento de competências específicas, dentre elas:

Utilizar processos e ferramentas matemáticas, inclusive tecnologias digitais disponíveis, para modelar e resolver problemas cotidianos, sociais e de outras áreas de conhecimento, validando estratégias e resultados; Agir individual ou cooperativamente com autonomia, responsabilidade e flexibilidade, no desenvolvimento e/ou discussão de projetos, que abordem, sobretudo, questões de urgência social, com base em princípios éticos, democráticos, sustentáveis e solidários, valorizando a diversidade de opiniões de indivíduos e de grupos sociais, sem preconceitos de qualquer natureza; Interagir com seus pares de forma cooperativa, trabalhando coletivamente no planejamento e desenvolvimento de pesquisas para responder a questionamentos e na busca de soluções para problemas, de modo a identificar aspectos consensuais ou não na discussão de uma determinada questão, respeitando o modo de pensar dos colegas e aprendendo com eles (Brasil, 2016b, p.267).

Dessa forma a BNCC exige do docente uma postura que estabeleça uma nova relação entre este e o conhecimento, uma vez que cabe a ele, primordialmente, a condução desse processo e essas exigências implicam em novas aprendizagens, no desenvolvimento de novas competências, em alteração de concepções, ou seja, na construção de um perfil profissional inovador, qualificado e dinâmico, capaz de mudar suas práticas para atender as necessidades atuais dos alunos.

Com base nos princípios das competências gerais estabelecidas pela BNCC, é requerido do licenciando a mobilização de conhecimentos, habilidades, atitudes e valores que devem ser utilizados para compreender e explicar a realidade, protagonizar escolhas e agir de forma colaborativa no intuito de promover o ensino-aprendizagem dentro da sua área de formação. Além disso, os cursos destinados à formação inicial de professores para a Educação Básica devem ter como fundamentos pedagógicos:

O compromisso com as metodologias inovadoras e com outras dinâmicas formativas que propiciem ao futuro professor aprendizagens significativas e contextualizadas em uma abordagem didático-metodológica alinhada com a BNCC, visando ao desenvolvimento da autonomia, da capacidade de resolução de problemas, dos processos investigativos e criativos, do exercício do trabalho coletivo e interdisciplinar, da análise dos desafios da vida cotidiana e em sociedade e das possibilidades de suas soluções práticas (Brasil, 2019, p. 5).

A pesquisa realizada por Stroher et al. (2018) apontou que muitos professores preferem utilizar metodologias tradicionais (aquelas que priorizam a transmissão de informações e tem sua centralidade na figura do professor), pois se sentem mais seguros em transmitir saberes e atividades que já desenvolveram. Entretanto, com modelo tradicional já tão desgastado, fica difícil atender os pressupostos básicos da BNCC. Seja no ensino básico ou superior, ainda se utiliza na maioria das vezes, de princípios, estratégias e procedimentos pedagógicos que não atendem às necessidades dos discentes do século XXI que 
estão imerso em um mundo digital, provocando desinteresse pelo ensino, pelos conteúdos aplicados e pela metodologia adotada pelo professor, ainda de forma predominantemente transmissiva e reprodutiva. Nesse contexto, para Moreira e Andrade:

As metodologias ativas surgiram com uma nova roupagem, uma nova denominação para tendências pedagógicas não tão novas assim, e se tornam a sensação do momento, como modelo educacional do século XXI, incorporado, sobretudo, por algumas Instituições de Ensino Superior que buscam minimizar lacunas de interesse e aprendizagem dos novos grupos que ingressam na universidade (Moreira \& Andrade, 2018, p.44).

Trata-se de um fato incontestável que todas as atividades humanas sofreram mudanças drásticas, em sua metodologia, enquanto a educação continuou estagnada em padrões na maneira como nossos estudantes devem aprender. As metodologias ativas vêm de encontro à essa estagnação, contudo, como salientam Feitosa e Valente (2021, p.6):

É importante salientar que a aplicação de uma metodologia ativa pelo professor necessita de um rigoroso planejamento e preparo, pois, ao contrário do que muitos pensam, essas metodologias têm uma complexidade muito maior que as aulas expositivas. Consideramos que, na atualidade, a teoria construída ou as discussões que desconsideram a possibilidade de ressignificação da prática pedagógica, do fazer docente, nega uma característica latente da humanidade: evoluir.

Diante do exposto, formulou-se a seguinte questão de pesquisa: as metodologias ativas, a rotação por estações e a instrução por pares, favorecem a gênese instrumental de professores de matemática em formação no âmbito do Programa Nacional de Formação de Professores da Educação Básica (PARFOR) e estimulam estes professores a replicá-las em suas respectivas salas de aula?

Desse modo, esta pesquisa teve como objetivo desenvolver uma oficina de formação, com o uso das metodologias ativas rotação por estações e a instrução por pares, para 20 professores de matemática do PARFOR, tendo como referência a Abordagem Instrumental de Rabardel (1995). O contexto do estudo foi um Workshop organizado pela coordenação do Curso de Graduação em Licenciatura em Matemática do PARFOR, da Universidade Federal do Amazonas (UFAM), no município de Itacoatiara, Estado do Amazonas.

Este trabalho está assim estruturado: Inicialmente apresentamos as finalidades e objetivos do programa PARFOR e no âmbito das metodologias ativas, são esclarecidos os princípios fundamentais das metodologias rotação por estações e instrução por pares; Em seguida apresentamos os pressupostos básicos da teoria da Abordagem Instrumental de Rabardel; Na seção seguinte, apresentamos a metodologia e o percurso metodológico descrevendo como se deu as atividades; Em seguida, fazemos uma análise dos dados coletados durante as atividades; Por fim apresentamos nossas considerações finais.

\section{O Programa PARFOR e as Metodologias Ativas}

O Programa Nacional de Formação de Professores da Educação Básica - PARFOR é um programa emergencial de formação de professores criado pelo governo Federal em regime de colaboração entre a União, o Distrito Federal, Estados e Municípios, pelo decreto n ${ }^{\circ}$ 6.755/2009 (Brasil, 2009), cujas diretrizes estão ancoradas no Plano de Metas Compromisso Todos pela Educação, instituído pelo decreto 6.094/2007, como programa estratégico do Plano de Desenvolvimento da Educação (PDE). O programa tem por objetivo ofertar de forma gratuita formação em nível superior de $1^{\mathrm{a}}$ Licenciatura, $2^{\mathrm{a}}$ Licenciatura e Formação Pedagógica para professores em exercício na rede pública de Educação Básica, conforme exigido pela Lei de Diretrizes e Bases da Educação (LDB).

O Programa funciona por meio de um calendário anual divulgado pela CAPES, determinando prazos, período e ações 
a serem concretizadas pelas secretarias de educação municipais, estaduais e do Distrito Federal, os Fóruns e as Instituições de Ensino Superior. Para se candidatar a uma vaga os professores têm de estar em exercício, há pelo menos 3 (três) anos, na rede pública da Educação Básica, estar cadastrado na Plataforma Freire e sua inscrição tem de ser validada pela Secretaria de Educação ou órgão análogo a que estiver ligado.

De acordo com o decreto $n^{\circ} 6.755 / 2009$ de sua criação entre os objetivos do programa estão, promover a melhoria da qualidade da educação básica e a atualização teórico-metodológica nos processos de formação dos profissionais do magistério inclusive no que se refere ao uso das tecnologias de informação nos processos educativos (BRASIL, 2009). Mais tarde este decreto foi revogado pelo decreto $\mathrm{n}^{\mathrm{o}} 8.752 / 2016$, que em suas disposições sobre a Política Nacional de Formação dos profissionais da Educação Básica traz entre os objetivos do programa:

Induzir avanços na qualidade da educação básica, assegurar o domínio dos conteúdos técnicos, científicos, pedagógicos e específicos pertinentes à área de atuação profissional e promover a atualização teórico-metodológica nos processos de formação dos profissionais da educação básica, inclusive no que se refere ao uso de tecnologias de comunicação e informação nos processos educativos. (Brasil, 2016a)

Diante do exposto, fica claro que, para atingir os objetivos do PARFOR, é necessário o desenvolvimento de metodologias inovadoras por parte dos professores em formação com o intuito de promover a melhoria da qualidade da educação básica. Portanto, as metodologias ativas, vão ao encontro dessa necessidade.

O advento das tecnologias de informação e comunicação (TIC) trouxe à tona algumas abordagens teóricas voltadas para os processos de ensino-aprendizagem, pautados nas principais teorias de aprendizagem, como a aprendizagem pela interação social, preconizada por Lev Vygotsky a aprendizagem pela experiência, de John Dewey, a aprendizagem significativa de David Ausubel, bem como a perspectiva freiriana da autonomia (Diesel et al., 2017). Os princípios básicos dessas teorias constituem a essência do que hoje denominamos metodologias ativas de aprendizagem.

Para Prince (2004) não é possível fornecer definições universalmente aceitas para todo o vocabulário da aprendizagem ativa, pois diferentes autores no campo interpretaram alguns termos de maneira diferente. No entanto, é possível fornecer algumas definições geralmente aceitas e destacar distinções em como termos comuns são usados.

Para Bonwell e Eison (1991) a aprendizagem ativa é geralmente definida como qualquer método instrucional que envolva os alunos no processo de aprendizagem e exige que realizem atividades de aprendizagem significativas e pensem no que estão fazendo. Na concepção de Valente et al. (2017) as metodologias ativas são:

Estratégias pedagógicas para criar oportunidades de ensino nas quais os alunos passam a ter um comportamento mais ativo, envolvendo-os de modo que eles sejam mais engajados, realizando atividades que possam auxiliar o estabelecimento de relaçães com o contexto, o desenvolvimento de estratégias cognitivas e o processo de construção de conhecimento (Valente et al. 2017, p.464).

Segundo Moran (2017), as metodologias ativas são estratégias de ensino centradas na participação efetiva dos estudantes na construção do processo de aprendizagem, de forma flexível, interligada, híbrida. Para esse pesquisador:

As metodologias ativas num mundo conectado e digital se expressam através de modelos de ensino híbridos, com muitas possíveis combinações. A junção de metodologias ativas com modelos flexíveis, híbridos traz contribuições importantes para o desenho de soluções atuais para os aprendizes de hoje (Moran, 2017, p.2).

A literatura acerca das metodologias ativas e seus benefícios é vasta e foge ao escopo deste trabalho nos aprofundarmos nesse aspecto. Nesta seção visamos a apresentar os princípios básicos das duas metodologias ativas que foram 
empregadas no experimento de ensino relatado, a saber, a modelo rotação por estações e a instrução por pares.

\subsection{Rotação por Estações}

A metodologia da rotação por estações é um dos modelos do que denominamos de ensino híbrido (blended learning). Staker e Horn (2012) definem ensino híbrido como um programa de educação formal que mescla momentos em que o aluno estuda os conteúdos e instruções usando recursos on-line, e outros em que o ensino ocorre em uma sala de aula, podendo interagir com outros alunos e com o professor.

Os modelos do ensino híbrido favorecem o aprendizado do aluno de acordo com suas possibilidades, uma vez que faz com que ele tenha mais autonomia e liberdade no momento de apropriar-se do conhecimento e, portanto, cada aluno se torna um membro ativo na sala de aula, compartilhando conhecimentos diversos e colaborando com o aprendizado dos demais alunos (Vergara et al., 2018). Segundo Silva et al. (2018):

O ensino híbrido proporciona o ajustamento e a adaptação às necessidades individuais de cada estudante, contribuindo para que haja a liberdade de escolha por parte dos estudantes das melhores formas e ferramentas, tanto para pesquisa quanto para sua apresentação e construção do conhecimento, permitindo que haja uma curiosidade para a pesquisa, motivação na realização das atividades e interesse nas aulas ministradas.

Programas de ensino híbrido são classificados como modelos de rotação se seus alunos participam de um curso ou matéria revezando-se entre as modalidades de ensino em um roteiro fixo ou a critério do professor, e onde pelo menos uma delas é o ensino online. Ao longo do dia, os alunos se revezam em um roteiro fixo entre o ensino online, lições em pequenos grupos com os professores mentores e lições em pequenos grupos com os professores de intervenção.

Para Staker e Horn, a variante rotação por estações satisfaz as quatro características de um híbrido, uma vez que representa uma combinação intergeracional do velho e do novo, é desenhada, em grande parte, com foco nos alunos existentes que aprendem tópicos centrais da educação formal em salas de aula tradicionais, preserva a função da sala de aula tradicional porque mantém os alunos em seus assentos na sala de aula por um número pré-determinado de minutos e não é notavelmente mais simples ou intuitiva que o sistema existente (Staker \& Horn, 2012).

\subsection{Instrução por Pares}

A metodologia denominada Peer Instruction, cuja tradução para o português é instrução por pares, foi desenvolvida pelo professor de Física Eric Mazur, da Universidade norte-americana Harvard no início de 1990. Esta metodologia visa o envolvimento dos alunos em seu próprio aprendizado durante a aula e concentra sua atenção nos conceitos subjacentes. Além disso, oferece oportunidade adequada para que os alunos pensem criticamente sobre os argumentos que estão sendo desenvolvidos.

Nesta metodologia, as aulas consistem em várias apresentações curtas sobre postos-chave e são intercaladas com perguntas conceituais, chamadas testes conceituais, projetadas para expor dificuldades comuns na compreensão do material. Esse processo força os alunos a refletir sobre os argumentos que estão sendo desenvolvidos e permite que eles avaliem sua compreensão dos conceitos antes mesmo de sair da sala de aula (Zhang et al., 2017).

Mazur (2015) ressalta que o Peer Instruction foge do conceito tradicional de dar uma aula detalhada, mas consiste em apresentar de forma curta os pontos-chave do conteúdo, seguido de pequenas questões conceituais para promover a interação entre os estudantes e focar a atenção deles nos conceitos fundamentais da disciplina. Com isso, segundo Mazur, os alunos obtêm ganhos significativos no entendimento conceitual (medido por testes padronizados), além de obter habilidades de resolução de problemas comparáveis às adquiridas nas aulas tradicionalmente ensinadas. 
Para cobrir um conceito-chave da aula, gasta-se um mínimo de 15 minutos. Para Mazur (1997), cada ponto principal da aula deve seguir os seguintes passos: (1) Exposição do conteúdo pelo instrutor (7-10 minutos); (2) Apresentar a questão aos alunos ( 1 minuto); (3) Os alunos pensam sobre o assunto ( 1minuto); (4) Gravar as respostas individuais dos alunos (opcional); (5) Os alunos discutem sobre os conceitos (1-3 minutos); (6) Gravar as respostas revisadas dos alunos (opcional); (7) O professor informa a resposta correta; (8) Explicar a resposta correta ( 2 minutos). O Quadro 1 detalha bem as etapas da metodologia instrução por pares.

Quadro 1 - Etapas do Peer Instruction.

\begin{tabular}{|l|l|}
\hline Etapas & Ações \\
\hline $1^{\text {a } \text { etapa }}$ & Os conceitos sobre um tema são apresentados por um curto período de tempo, em no máximo 15 minutos sem interrupção. \\
\hline $2^{\text {a } \text { etapa }}$ & Exibição de uma questão de múltipla escolha sobre o tema apresentado. \\
\hline $3^{\text {a } \text { etapa }}$ & Os alunos são informados que têm 3 minutos para ler e responder a questão. \\
\hline $4^{\text {a } \text { etapa }}$ & Os alunos escolhem a alternava que consideram correta, levantando simultaneamente flash cards com as letras A, B, ou C. \\
\hline $5^{\text {a etapa }}$ & O professor avalia a respostas e informa a classe sobre a distribuição geral de respostas. \\
\hline $6^{\text {a } \text { etapa }}$ & $\begin{array}{l}\text { Se a maioria dos alunos escolheu a resposta certa (caso em que a percentagem de acertos ultrapasse 70\%), o professor } \\
\text { confirma e passa para a próxima questão. Se a percentagem for menos de } 30 \%, \text { sugere que o aluno não compreendeu o } \\
\text { conceito. O professor, então, pode explicar novamente com uma nova abordagem e lançar outro teste conceitual. }\end{array}$ \\
\hline $7^{\text {a etapa }}$ & $\begin{array}{l}\text { Caso ocorra grande divergência nas respostas (isto é, a percentagem de acertos está na margem de } 30 \% \text { a 70\%), isso é sinal } \\
\text { de que a questão é desafiante, porém não tão difícil. Nesse caso, pede-se que os alunos discutam suas respostas com os } \\
\text { colegas e tentem convencê-los. Após alguns minutos, é tempo para uma segunda votação e o professor deve estabelecer um } \\
\text { tempo de aproximadamente } 2 \text { minutos para que cada aluno defenda sua resposta com o colega ao seu lado. }\end{array}$ \\
\hline $8^{\text {a etapa }}$ & $\begin{array}{l}\text { Depois trazer as discussões sobre as respostas a classe então escolhe novamente a resposta. A classe então vota a resposta } \\
\text { novamente e voltamos para a etapa 5. }\end{array}$ \\
\hline $9^{\text {a etapa }}$ & $\begin{array}{l}\text { Se a proporção de alunos com a resposta certa aumentou após a discussão, o professor pode confirmá-la e passar para o } \\
\text { próximo tópico ou questão. Se não, o professor pode querer explicar a resposta certa antes de passar. }\end{array}$ \\
\hline
\end{tabular}

Fonte: Adaptado de Butchart, Handfield e Restall (2009).

\section{Referencial Teórico}

Esta pesquisa tem como referencial teórico subjacente a Abordagem Instrumental, teoria desenvolvida pelo pesquisador francês Rabardel de Pierre Rabardel, cujo foco está centrado na Gênese Instrumental. Apoiada em elementos da psicologia, a teoria da instrumentação fornece elementos apropriados para investigar a ação do sujeito na transformação de um artefato em instrumento.

Rabardel (1995) descreve as relações que existem entre o sujeito, a ferramenta (artefato) e os esquemas de utilização. O sujeito pode ser um indivíduo ou grupo de indivíduos que desenvolvem a ação ou são escolhidos para o estudo. O artefato é um dispositivo que pode ser material (lápis, computador, sólidos geométricos em acrílico etc.) ou simbólico (uma fórmula matemática, uma figura, um gráfico etc.). Rabardel (1995) utiliza o termo esquemas de utilização, de acordo com Vergnaud (1996), “[...] é uma organização invariante de comportamentos para classes de situações”. É necessário procurar nos esquemas os elementos cognitivos que permitem que a ação do sujeito seja operatória.

Entende-se, portanto, que o artefato corresponde ao objeto por si só, com características próprias e de caráter estático. Quando o sujeito agrega a esse artefato um esquema de utilização e o incorpora às suas atividades, dá origem a um instrumento e esse processo de transformação do artefato em instrumento é denominado de Gênese Instrumental (Rabardel, 1995). Portanto, para Rabardel (1995), o instrumento é uma entidade mista com dois componentes: o artefato, produzido para o sujeito e os esquemas de utilização associados, que são resultados de uma construção do próprio sujeito ou de uma apropriação de esquemas de utilização já existentes.

Rabardel (1995) denomina como esquemas de utilização os esquemas relacionados ao uso do artefato e esses esquemas tem relação com duas dimensões da atividade. A primeira diz respeito às atividades relacionadas às tarefas secundárias, que são as tarefas relativas à gestão das características e propriedades particulares do artefato. Nesse caso, os 
esquemas são definidos como esquemas de uso. A segunda tem a ver com atividades primárias que são orientadas ao objeto da atividade, na qual o artefato é um meio de concretização e de realização. Nesse caso, os esquemas são definidos como esquemas de ação instrumental.

Uma vez que sujeitos imersos em uma atividade colaborativa valem-se de esquemas de utilização e coordenam ações individuais e a integração de seus resultados para atender aos objetivos de um coletivo, emergem os esquemas de atividade coletiva instrumental (Rabardel, 1995). Logo, os esquemas de utilização possuem uma dimensão privada e outra social, visto que o coletivo trabalha com um instrumento ou com uma mesma classe de instrumentos.

Uma vez que o foco de interesse de Rabardel (1995) é a transformação de um artefato em um instrumento, ele propõe o modelo SAI (Situações de Atividades Instrumentais) (Figura 1), descrevendo as relações entre o sujeito (aquele que dirige a ação psíquica sobre o objeto) e o objeto (sobre ele que a ação é dirigida) mediado pelo instrumento (que é o mediador entre o sujeito e o objeto). Esse modelo evidencia as várias interações que intervêm nas atividades instrumentais: sujeito-objeto [S-O], sujeito-instrumento [S-i], instrumento-objeto [i-O] e sujeito-objeto mediada pelo instrumento [S(i)-O], que se desenvolvem em um ambiente formado pelo conjunto de condições que o sujeito deve levar em conta para realizar sua atividade.

Figura 1 - Modelo de Situações de Atividades Instrumentais.

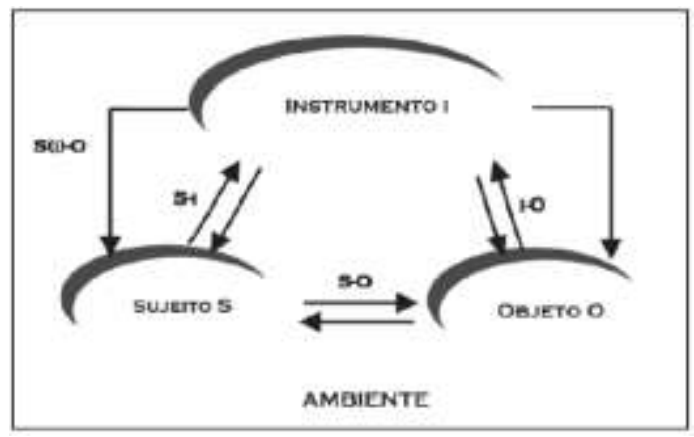

Fonte: Rabardel (1995, p. 65).

A gênese instrumental é caracterizada por dois processos elementares, a instrumentalização e a instrumentação. Embora sejam processos com definições diferentes, Trouche (2004) afirma que são interdependentes e que diferenciá-los é indispensável para a análise da gênese instrumental.

A instrumentalização ocorre quando o sujeito insere o artefato em sua prática na intenção de conhecer suas propriedades, sua interface e funcionalidades, desenvolvendo assim esquemas de uso. No entanto, quando o indivíduo atribui funções aos artefatos, os esquemas de ação de uso ou esquemas mentais evoluem, dando origem às novas formas de utilização do artefato, surge então o instrumento. Quando isto ocorre, tem-se o processo de instrumentação do sujeito que passa a integrar de fato o instrumento à sua prática. (Rabardel,1995, p.93).

Zuchi (2008) caracteriza a instrumentação como um processo pelo qual as especificidades e as potencialidades de um artefato vão condicionar as ações de um sujeito para resolver um dado problema e a instrumentalização (orientada para o artefato), tem relação com o enriquecimento das propriedades do artefato e se caracteriza como um processo pelo qual o sujeito modifica, adapta ou produz novas propriedades, personalizando o artefato de acordo com suas demandas.

É necessário enfatizar que estes dois processos, instrumentalização e instrumentação, são complementares e, de certo modo, cíclicos e evolui segundo as situações nas quais a ação do sujeito é envolvida. Durante a instrumentalização, na qual o sujeito insere o artefato para conhecer suas características e desenvolver esquemas de uso, acontece tanto a priori, quanto a posteriori a instrumentação. E, à medida que se utiliza o instrumento, novas necessidades e obstáculos fazem surgir novos esquemas de uso, formulados pelo sujeito. 
Assim retomando o foco do estudo referente ao processo de gênese instrumental de professores em formação no PARFOR em um ambiente de metodologias ativas, ao utilizar a teoria da Instrumentação como aporte teórico, buscamos analisar como ocorre o processo de gênese instrumental, por parte dos docentes, ao vivenciarem uma oficina cujo objeto são os sólidos geométricos.

\section{Metodologia}

Esta pesquisa tem uma abordagem qualitativa. Segundo Creswell (2010, p. 26):

A pesquisa qualitativa é um meio para explorar e para entender o significado que os indivíduos ou os grupos atribuem a um problema social ou humano. O processo de pesquisa envolve as questões e os procedimentos que emergem, são dados tipicamente coletados no ambiente do participante, a análise dos dados indutivamente construída a partir das particularidades para os temas gerais e as interpretações feitas pelo pesquisador acerca dos significados dos dados.

Quanto aos objetivos, trata-se de uma pesquisa descritiva que, segundo Gil (2008, p. 28), "tem como objetivo primordial a descrição das características de determinada população ou fenômeno ou o estabelecimento de relações entre variáveis". Quanto aos procedimentos, podemos classificar este estudo como uma pesquisa-ação, que, segundo a definição de Thiollent (1985, p. 14) "é um tipo de pesquisa social com base empírica que é concebida e realizada em estreita associação com uma ação ou com a resolução de um problema coletivo e no qual os pesquisadores e os participantes representativos da situação ou do problema estão envolvidos do modo cooperativo ou participativo".

Esta experiência foi vivenciada em duas oficinas com 20 acadêmicos do segundo período do curso de Licenciatura em Matemática pelo PARFOR/UFAM no município de Itacoatiara-Am, dentro de um Workshop promovido pela coordenação do Curso. Ressaltamos que estes acadêmicos são professores da rede pública de ensino. Um questionário com perguntas abertas e fechadas foi elaborado no Google Formulário e aplicado com o objetivo de traçar um perfil do público da pesquisa. Ao final aplicamos outro questionário visando a registrar as impressões acerca das atividades.

A primeira aula ocorreu no dia 05 de março de 2020 a qual iniciamos com uma palestra que durou 1 hora e tratamos de esclarecer o que são as metodologias ativas com destaque para o modelo de ensino híbrido, rotação por estações e a metodologia instrução por pares.

Apresentamos aos professores os princípios básicos de cada uma dessas duas metodologias e a forma como seriam desenvolvidas. Em seguida, realizamos uma aula com a metodologia rotação por estações. $\mathrm{O}$ objeto matemático abordado foi sólidos geométricos, a atividade teve a duração de 3h e utilizamos como recursos materiais uma ficha de atividades (Figura 2), régua, calculadora, sólidos geométricos em acrílico, celular e um notebook com acesso a internet.

Figura 2 - Parte da ficha de trabalho usada na aplicação da metodologia rotação por estações.

\section{Ficha de Trabalho}

\begin{tabular}{|c|c|c|c|c|c|c|c|c|}
\hline $\mathrm{N}^{\circ}$ & Classificaçāo & $\begin{array}{l}N^{\circ} \text { de } \\
\text { Vertices }\end{array}$ & $\begin{array}{l}\mathrm{N}^{\circ} \text { de } \\
\text { Arestas }\end{array}$ & $\begin{array}{l}N^{0} \text { de } \\
\text { faces }\end{array}$ & $\begin{array}{l}\text { Area } \\
\text { Lateral }\end{array}$ & $\begin{array}{l}\text { Area da } \\
\text { Base }\end{array}$ & $\begin{array}{l}\text { Area } \\
\text { Total }\end{array}$ & Volume \\
\hline 1 & & & & & & & & \\
\hline 2 & & & & & & & & \\
\hline 3 & & & & & & & & \\
\hline 4 & & & & & & & & \\
\hline 5 & & & & & & & & \\
\hline
\end{tabular}

Fonte: Elaborada pelos autores. 
Na configuração didática, a sala de aula foi organizada em 6 "estações" e os professores foram divididos em 5 grupos. Os sólidos foram assim distribuídos: Primas (estações 1 e 2), Pirâmides (estação 3), Cilindros (estação 4) e Cones (estação 5). Na Figura 3 temos um registro dos acadêmicos trabalhando na estação 1.

Figura 3 - Professores trabalhando na estação dos prismas.

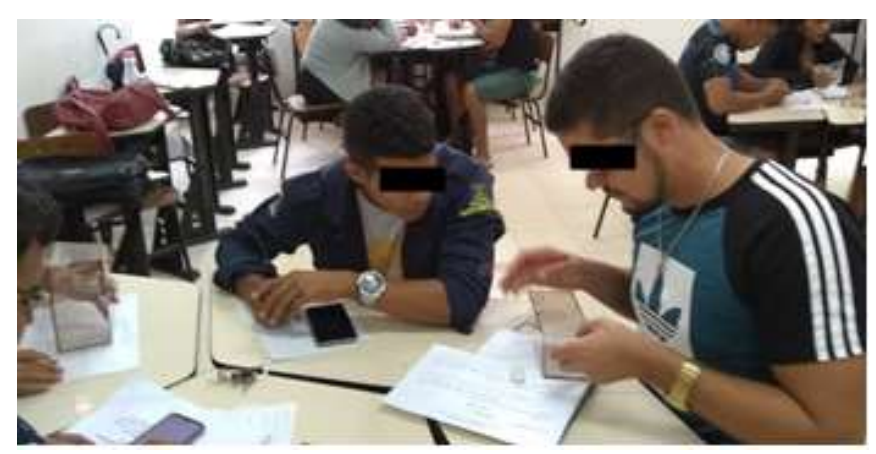

Fonte: Elaborada pelos/as autores(as).

A estação 6 contava com uma atividade on-line onde os professores tinham que responder à perguntas acerca dos sólidos geométricos (Figura 4). No início da atividade, a estação 6 ficou vazia. Apenas a partir da segunda rotação, que passou a ocupada pelos grupos. Os professores tinham 30 minutos para trabalhar em cada uma das estações e ao final da aula cada equipe escolhia a atividade de alguma das estações para fazer uma breve apresentação (Figura 5).

Figura 4 - Discentes trabalhando na estação tecnológica.

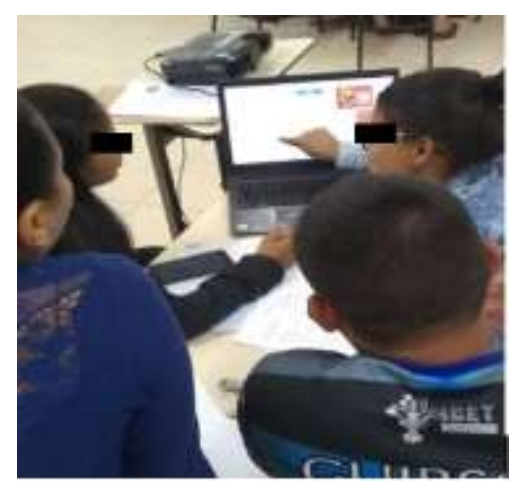

Fonte: Elaborada pelos autores.

Figura 5 - Discentes apresentando sua atividade.

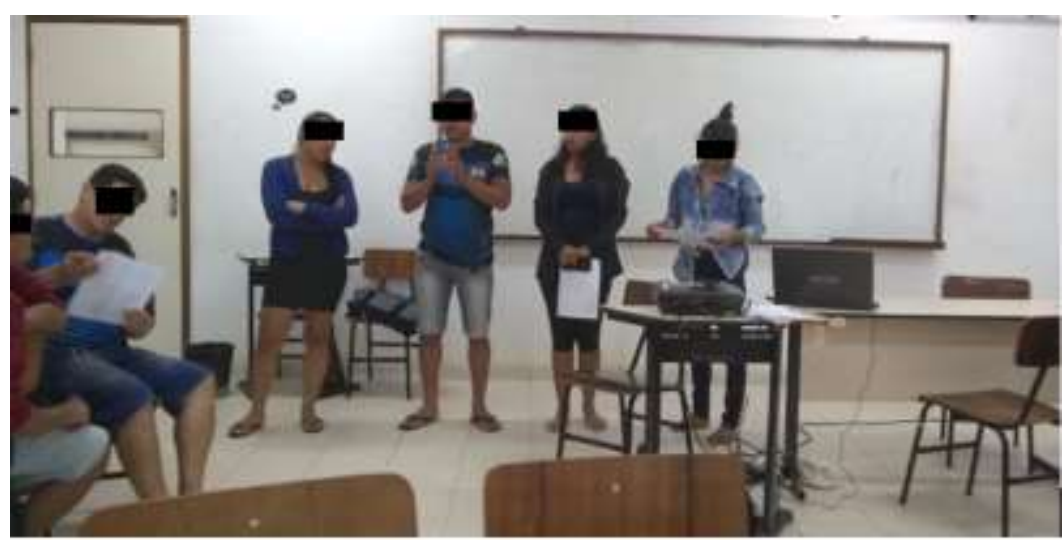

Fonte: Elaborada pelos autores. 
Ao término das apresentações, passamos as orientações para a aula seguinte, na qual aplicaríamos a metodologia instrução por pares e reforçamos a necessidade da preparação prévia para a aula. A componente matemática a ser estudada foi Geometria Plana e os tópicos para estudo foram: Noções e proposições primitivas, segmento de reta e ângulos. Como recurso material foi utilizado o livro (Dolce \& Pompeu, 2013).

A metodologia instrução por pares foi aplicada na segunda aula e ocorreu no dia 6 de março de 2020. A aula foi dividida em três momentos, um para cada tópico: Noções e proposições primitivas, Segmento de reta e Ângulos. Cada tópico era explanado brevemente e em seguida aplicado testes conceituais seguindo as etapas da metodologia instrução por pares. Os professores escolhiam a alternava que considerava correta, levantando simultaneamente cartões com as letras A, B, ou C. Foram seguidas todas as etapas descritas no Quadro 1.

\section{Resultados e Discussão}

Iniciaremos esta seção apresentando o perfil e as impressões dos partícipes da pesquisa acerca das atividades desenvolvidas. Dos 20 (vinte) professores que participaram das atividades, 15 (quinze) responderam ao questionário, sendo 8 (oito) mulheres e 7(sete) homens e a média de idade é de 33,1 anos. Dos 15 professores, 5(cinco) responderam não ter lecionado em 2019 e dos 10 (dez) que afirmaram ter lecionado, a média é de 8,6 anos de atuação e 8 (oito) disseram atuar em escolas da zona rural do município. Em relação ao nível de escolaridade em que atuaram em 2019, apenas 6\%, o que corresponde a 1 professor, afirmou ter atuado no Ensino Médio.

Quando perguntados sobre os motivos que os fizeram escolher o curso de Licenciatura em Matemática, 9 (nove) responderam que foi o gosto pela Matemática. Acerca do seu grau de satisfação com curso, 66,7\% afirmaram estar totalmente satisfeito ou satisfeitos e quanto ao nível de dificuldade encontrado no curso até o momento, 53,3\% afirmaram ter sido extremamente ou razoavelmente difícil.

Apenas $20 \%$ afirmaram já ter ouvido falar sobre as metodologias ativas. Em relação às metodologias utilizadas nas atividades, 93,3\% achou a metodologia da rotação por estações mais interessante, sendo esta também a que mais os professores $(86,7 \%)$ se sentem mais confiantes em aplicar em suas turmas. A seguir, nossa análise à luz da abordagem instrumental, sobre cada uma das atividades.

Na primeira aula, aplicamos a metodologia rotação por estações e o primeiro fato observado foi o desconhecimento por parte de muitos dos professores acerca dos sólidos geométricos. Dúvidas sobre, classificação e elementos dos sólidos, cálculo de áreas e volumes, foram percebidas em todas as equipes.

Diante desse primeiro obstáculo, solicitamos que os membros de cada equipe discutissem entre si para ver se algum deles sabia como resolver o problema. Caso nenhum deles soubesse, a orientação era que fizessem uso dos celulares e buscassem as respostas na internet. Após a consulta e a possível resposta encontrada, os grupos eram orientados a chamar o professor para relatar o que encontraram e a solucionar o problema em definitivo. Isto foi feito durante toda a atividade, isto é, incentivá-los a buscar as respostas e não ficar esperando que o professor lhes desse a resposta imediatamente. Percebe-se aqui o processo de instrumentalização, uma vez que os sujeitos estavam buscando o enriquecimento das propriedades do artefato (sólidos geométricos feitos de acrílico). Evidenciou-se também os esquemas de uso, uma vez que se tratava de uma atividade secundária.

Essa estratégia foi discutida ao final da aula, mostrando aos professores que isso deveria ser feito nas suas respectivas salas de aula, de modo a ensinar aos seus alunos a buscarem as respostas e não ficar na dependência apenas do professor. Outro ponto que merece destaque nessa primeira metodologia foi o modo como fizemos uso dos recursos disponíveis. Vejamos o exemplo de uma das atividades: Calcular o volume de uma pirâmide de base triangular regular feita em acrílico. 
Primeiramente, os professores fizeram uso do aparelho celular para acessar a internet em busca de pesquisar como se calcula o volume de uma pirâmide qualquer (instrumentalização). Uma vez encontrada a expressão algébrica correspondente ( $\mathrm{V}=1 / 3$ (área da base).(altura)), os acadêmicos tinham que calcular estes elementos, área da base e altura, da pirâmide fazendo uso de régua e calculadora (instrumentação). Percebeu-se aqui os esquemas de ação instrumental.

A colaboração entre os acadêmicos foi um aspecto importante e a relevância dada neste estudo para as atividades colaborativas apoia-se numa vasta literatura que aponta uma gama de benefícios, tais como, o compartilhamento de modelos mentais e conhecimentos, avançando na compreensão do assunto tratado em aula (Jeong \& Chi,1997) e a contribuição para a criação de questionamentos sobre as estruturas de conhecimentos já adquiridos e enriquece o repertório de pensamento e a ação dos estudantes (Damiani, 2006). Em todos os grupos de trabalho as discussões em torno das tarefas propostas eram constantes, não apenas entre os membros do próprio grupo, mas também entre membros de grupos distintos, evidenciando a emersão dos esquemas de atividade coletiva instrumental.

$\mathrm{Na}$ segunda aula, aplicamos a metodologia instrução por pares e o aspecto da colaboração ganhou mais evidência devido à especificidade da metodologia que desencadeia estratégias de formação processuais, coletivas e dinâmicas. Nos testes conceituais com percentuais de acerto entre $30 \%$ e $70 \%$, cada um era levado a refletir com os demais colegas e compartilhar erros e acertos, e novamente os esquemas de atividade coletiva instrumental ficaram bem evidentes quando os grupos tinham que negociar significados e confrontar pontos de vista.

Apesar dos professores terem demonstrado algumas fragilidades em relação aos conhecimentos matemáticos abordados durante a atividade, como não saber algumas das noções e proposições primitivas da Geometria Plana, segmento de reta e ângulos, a aplicação da instrução por pares ocorreu de forma tranquila e durante a atividade cada um defendia seu ponto de vista, mas sempre se mostrando receptivo às ideias dos colegas, tornando o debate saudável. Isso corroborou com o comportamento esperado dos partícipes de uma atividade de instrução por pares (Araujo \& Mazur, 2013).

\section{Considerações Finais}

Este estudo buscou responder à seguinte questão: As metodologias ativas, rotação por estação e instrução por pares, favorecem a gênese instrumental de professores de matemática em formação no âmbito do Programa Nacional de Formação de Professores da Educação Básica (PARFOR) e estimulam estes professores a replicá-las em suas respectivas salas de aula?

Para responder à essa questão, traçamos como objetivo conceber e analisar uma oficina pautada nas metodologias ativas rotação por estações e a instrução por pares tendo com referencial teórico subjacente a Abordagem Instrumental de Pierre Rabardel, com foco na Gênese Instrumental. A oficina foi vivenciada por 20 professores em formação do curso de Licenciatura em Matemática do Plano Nacional de Formação de Professores da Educação Básica (PARFOR) e a atividade ocorreu no município de Itacoatiara em duas aulas de 4h cada, durante um Workshop organizado pela coordenação do referido curso.

A proposta das atividades foi proporcionar aos professores em formação a oportunidade de vivenciar na prática as metodologias ativas rotação por estações e instrução por pares. Pensamos que dessa maneira, aumentam-se as chances deles, que são professores do Ensino Básico, replicarem as metodologias com seus alunos. Isso de fato se confirmou a partir das respostas dadas pelos professore ao formulário aplicado.

Os conteúdos matemáticos abordados na aplicação da metodologia rotação por estações foi cálculo de áreas e volumes de sólidos geométricos (prismas, pirâmides, cilindros, cones e esfera), enquanto que, noções e proposições primitivas da Geometria Plana, segmento de reta e ângulos, foram abordados na aplicação da metodologia instrução por pares.

Dentre as duas metodologias, a rotação por estações foi a que mais entusiasmou os professores e a que mais eles se sentiram confiantes em agregar ao seu repertório de recursos. Foram observadas algumas dificuldades em relação aos 
conteúdos matemáticos abordados e acreditamos que isso seja reflexo do fato de a grande maioria atuar no Ensino Fundamental ficando e que possivelmente estudaram estes conteúdos somente enquanto estudantes do Ensino Médio.

A dificuldade observada no parágrafo anterior foi superada por meio do trabalho colaborativo estimulado pelas duas metodologias empregadas e pelo uso de recursos tecnológicos, como o a aparelho celular e a internet. Vimos aqui a oportunidade de mostrar para estes professores a importância de não fornecer respostas prontas aos seus alunos, mas sim, orientá-los na busca dessas respostas.

Chamamos a atenção para o fato de que, assim como durante as atividades eles trabalharam colaborativamente, a colaboração deveria fazer parte de sua prática docente visto que é importante o compartilhamento de experiência entre professores, pois isso favorece o desenvolvimento da sua destreza na análise crítica, na resolução de problemas e na tomada de decisões.

Foi possível constatar o processo da instrumentalização, nos momentos em que os professores buscavam se apropriar de conceitos e propriedades matemáticas relacionadas ao estudo dos sólidos geométricos (classificação e elementos dos sólidos, cálculo de áreas e volumes), por meio de consultas realizadas na internet com suporte do celular, dos sólidos geométricos em acrílico e pela discussão com seus pares e pela busca de conhecer as funcionalidades de calculadoras científicas. A instrumentação ocorreu nos momentos em que os professores tentavam resolver as situações propostas, como, por exemplo, calcular o volume e a área dos sólidos. Assim, se pode perceber que o processo da gênese instrumental de fato ocorreu. Além disso, o ambiente de aprendizagem colaborativa propiciado pelas metodologias ativas empregadas favoreceu a emersão dos esquemas de atividade coletiva instrumental que ocorreu durante as discussões em torno das tarefas propostas.

A literatura acerca das metodologias ativas é vasta, assim como os trabalhos que apontam seus benefícios para o processo ensino-aprendizagem. Entretanto, se queremos que estas metodologias promovam uma mudança significativa na prática dos professores do Ensino Básico, devemos implantá-las nos cursos de formação inicial e continuada, sempre suportadas por teorias, fazendo com que eles vivenciem na prática estas metodologias, pois só assim estarão aptos a replica-las em suas salas de aula.

\section{Referências}

Araujo, I. S., \& Mazur, E. (2013). Instrução pelos colegas e ensino sob medida: uma proposta para o engajamento dos alunos no processo de ensinoaprendizagem de Física. Caderno brasileiro de ensino de física. Florianópolis. 30(2), 362-384.

Brasil (2009). Ministério da Educação. Decreto nº 6.755, de 29 de janeiro de 2009. Institui a Política Nacional de Formação de Profissionais do Magistério da Educação Básica.

Brasil (2016a). Ministério da Educação. Decreto n 8.752, de 09 de maio de 2016. Dispõe sobre a Política Nacional de Formação de Profissionais da Educação Básica.

Brasil (2016b). Ministério da Educação. Secretaria da Educação Básica. Base nacional comum curricular.

Brasil (2019). Ministério da Educação. Conselho Nacional de Educação. Conselho Pleno. Resolução n 2, de 20 de dezembro de 2019. Define as Diretrizes Curriculares Nacionais para a Formação Inicial de Professores para a Educação Básica e institui a Base Nacional Comum para a Formação Inicial de Professores da Educação Básica (BNC-Formação).

Butchart, S., Handfield, T., \& Restall, G. (2009). Using Peer Instruction to Teach Philosophy, Logic, and Critical Thinking. Teaching Philosophy, 32(1), 140. https://doi.org/10.5840/teachphil20093212.

Diesel, A., Baldez, A., \& Martins, S. (2017). Os princípios das metodologias ativas de ensino: uma abordagem teórica. Revista Thema, 14(1), 268288. https://doi.org/10.15536/thema.14.2017.268-288.404.

Bonwell, C. C., \& Eison, J. A. (1991). Active Learning: Creating Excitement in the Classroom. 1991 ASHE-ERIC Higher Education Reports. ERIC Clearinghouse on Higher Education, The George Washington University, One Dupont Circle, Suite 630, Washington, DC 20036-1183.

Creswell, J. W. \& Creswell, J. D. (2021). Projeto de pesquisa-: Métodos qualitativo, quantitativo e misto. Penso Editora.

Damiani, M. F. (2006). A teoria da atividade como ferramenta para entender o desempenho de duas escolas de ensino fundamental. Reunião Anual da ANPED, 29, 1-15. 
Research, Society and Development, v. 10, n. 16, e462101623970, 2021

(CC BY 4.0) | ISSN 2525-3409 | DOI: http://dx.doi.org/10.33448/rsd-v10i16.23970

Dolce, O. \& Pompeo, J. N. (2013). Fundamentos de matemática elementar. Atual, 9.

Feitosa, F. E. da S. \&Valente, A. A. P. (2021). Active Methodologies: an innovation that may become fashionable. Research, Society and Development, 10(14), e330101422046. https://doi.org/10.33448/rsd-v10i14.22046.

Gil, A. C. (2008). Métodos e técnicas de pesquisa social. (6a ed.), Editora Atlas SA.

Jeong, H., \& Chi, M. T. (1997). Construction of shared knowledge during collaborative learning.

Mazur, E. (2015). Peer instruction: a revolução da aprendizagem ativa. Penso Editora.

Mazur, E. (1997, March). Peer instruction: Getting students to think in class. In AIP Conference Proceedings. 399(1), 981-988. American Institute of Physics.

Moran, J. (2017). Metodologias ativas e modelos híbridos na educação. Novas Tecnologias Digitais: Reflexões sobre mediação, aprendizagem e desenvolvimento. Curitiba: $C R V, 23-35$.

Moreira, M. A., \& de Moura Andrade, M. C. (2018). Metodologias ativas no Ensino Superior: possibilidade ou "faz de conta"? Revista Evidência, 14(15).

Prince, M. (2004). Does active learning work? A review of the research. Journal of engineering education, 93(3), $223-231$.

Rabardel, P. (1995). Les hommes et les technologies; approche cognitive des instruments contemporains (p. 239). Armand Colin.

Staker, H., \& Horn, M. B. (2012). Classifying K-12 blended learning.

Stroher, J. N., Henckes, S. B. R., Gewehr, D., \& Strohschoen, A. A. G. (2018). Estratégias pedagógicas inovadoras compreendidas como metodologias ativas. Revista Thema, 15(2), 734-747.

da Silva, D. D. S. F., Nunes, J. F., Marques, I. L., \& Marques, N. L. R. (2018). Ensino híbrido com a utilização da plataforma Moodle. Revista Thema, 15(3), $1175-1186$.

Trouche, L. (2004). Environnements Informatisés et Mathématiques: quels usages pour quels apprentissages? Educational Studies in Mathematics, 55(1), 181197.

Thiollent, M. J. (1985). Metodologia da pesquisa-ação na instituição educativa.

Valente, J. A., de Almeida, M. E. B., \& Geraldini, A. F. S. (2017). Metodologias ativas: das concepções às práticas em distintos níveis de ensino. Revista Diálogo Educacional, 17(52), 455-478.

Vergara, A. C. E., Hinz, V. T., \& Lopes, J. L. B. (2018). Como Significar a Aprendizagem de Matemática Utilizando os Modelos de Ensino Híbrido. Revista Thema, 15(3), 885-904.

Zhang, P., Ding, L., \& Mazur, E. (2017). Peer Instruction in introductory physics: A method to bring about positive changes in students' attitudes and beliefs. Physical Review Physics Education Research, 13(1), 010104.

Zuchi, I. (2008). A integração dos ambientes tecnológicos em sala: novas potencialidades e novas formas de trabalho. Simpósio Internacional De Pesquisa Em Educação Matemática, 2. 